The 3rd International Conference on Biological Science 2013

(The 3rd ICBS-2013)

\title{
CHARACTERIZATION OF CHROMOSOME OF STRIPPED KEELBACK Xenochrophis vittattus (Linnaeus, 1758) FROM PIYUNGAN, BANTUL, DAERAH ISTIMEWA YOGYAKARTA
}

\author{
Berry Fakhry Hanifa ${ }^{1}$, Niken Satuti Nurhandayani ${ }^{2}$ \\ ${ }^{1}$ Post-graduate Sudent, Faculty of Biology, Universitas Gadjah Mada \\ ${ }^{2}$ Laboratory of Genetic, Faculty of Biology, Universitas Gadjah Mada \\ Correspondence email: hanifa.awesome@gmail.com
}

\begin{abstract}
Indonesia is a tropical country which has varies of habitat types that are dispersed into thousands islands. The diversity and its tropical climate, makes Indonesia as a suitable place as a natural habitat for herpetofauna, especially Sub Order Serpentes. Xenochrophis vittattus (Linnaeus, 1578), called stripped keelback snakes, is a semi-aquatic snakes spread in Indonesia, especially in Java, Sumatra, Bangka, and Manado, and commonly used as pet. Since there are few reports on genetic studies, especially in the field of karyology, this study aims to characterize the chromosomes of stripped keelback from Piyungan population, Bantul, Yogyakarta. This study used a brief splash of blood cultures method. This has been known as the first stripped keelback cytological study in Indonesia. The results showed that striped keelback has a diploid chromosome $(2 n)=34$, consists of metacentric chromosome (number 1, 2, 3, 4, 19, 20, 21, 22, 23, 24, 25, and 26); submetacentric chromosome (number 5, 6, 7, 8, 9, 10, 11, 12, 13, 14, 15, 16, 17, and 18). Whereas the chromosome number 27, 28, 29, 30, 31, 32, 33, and 34 were micro chromosomes. Striped keelback karyotype formula was $2 \mathrm{n}=2 \mathrm{x}=34=12 \mathrm{~m} 14 \mathrm{sm} 8$ micro chromosomes. The longest chromosome of stripped keelback was $2.9335 \pm 0.1772 \mathrm{um}$, whereas the shortest one was $0.5088 \pm 0.013$ um, and the R value was $5.9106 \pm 1.1265$.
\end{abstract}

Key words: Xenochrophis vittattus, Stripped keelback, chromosome characterization, karyotype

\section{INTRODUCTION}

Xenochrophis vittattus well known as Striped keelback is a semi aquatic snake inhabit pool body water especially rice farm. Striped keelback also known as Lareangon (Shepherd) in java language. Striped keelback is classified in Colubridae, Natricinae, including most of semi aquatic Colubrid. Striped keelback has two brownish strips on its back covered by solid black which has black-white mottle ventral scale, it is quite popular and has potential to be exposed as pet due to its stunning pattern.

Study about this snake has been conducted involving characterization of scale, including head scales identification; ventral, sub caudal and anal scales numeration; and also length comparison through morphometric (Bergman, 1950; Gazali, 1914; Hoesel, 1959; Rooij, 1915). But, there is no deeper study to be conducted yet about this snake on taxonomic field.

Cytological study can support taxonomic based research on organism due to their unique chromosomal characterization (Cole \& Gans, 1997). Research about characterization of chromosome of Natricinae has been done before for some Species in Natrix group and showed about 18-21 pair of chromosome (Eberle, 1971.; Rossman \& Eberle, 1977), whereas Trinco \& Smith (1971) found 17-18 pair of chromosome of Natrix natrix, and Itoh et al. (1970) found about 17-20 pair of chromosome on a different species. But until recent time, the research about characterization of chromosome of Xenochrophis vittattus yet to be found. 
This research aims to figure chromosomal character of this snake.

\section{MATERIALS AND METHODS}

Chromosome characterization of Xenochrophis vittattus was conducted by collecting blood sample of specimens gathered through wild collection and collected from snakes trader. Wild caught snake was obtained from rice farm in Piyungan, Bantul, Daerah Istimewa Yogyakarta and from snake trader in Pasar PASTI, Bantul, Daerah Istimewa Yogyakarta and maintained in terrarium as required. Blood collecting conducted by wiping snakes tail using $70 \%$ ethanol before collected by syringe $(3 \mathrm{ml})$ through its vein at 7-9 am. Blood samples were placed in tube which contained 2\% EDTA and mixed firmly. Blood containing tube then be placed in ice box for short distance travel or directly cultured.

Blood sample was cultured in $7 \mathrm{ml}$ Dulbesco's Moddified Eagle Medium (DMEM) of which containing antimicotic and antibiotic including 0,1-0,2 ml Phytohemaglutinin (PHA) as mitotic enhancement agent, solution then be placed in flask culture and mixed firmly and incubated at $37 \pm 0,5^{\circ} \mathrm{C}$ with $5 \% \mathrm{CO}_{2}$ for 72 hours, while in the incubator, the flask cover is loosened and the culture were mixed everyday.

Chromosomes were obtained by modifying Amemiya et al. (1984). Blood were harvested after being cultured for 72 hours. Amount of $0,5-1 \mathrm{ml}$ Colchicines were added 2 hours before harvesting while the flask being mixed firmly every 30 minutes. Cultures were centrifuged by $750 \mathrm{G}$ for 10 minutes and supernatant was replaced by $4 \mathrm{ml}$ of $0,56 \% \mathrm{KCL}$ and cultured cells were left for about 1 hour and being firmly mixed every 15 minutes. Cultured cell added by $2 \mathrm{ml}$ of carnoys solution and centrifuged by $750 \mathrm{G}$ for 10 minutes. Centrifugation and replacement of supernatant were repeated twice more before fixed by $1-1,5 \mathrm{ml}$ of carnoys solution.

Cell suspension were splashed on $15-20 \mathrm{~cm}$ high distance against object glass and left behind until dry. Staining was conducted by dropping $20 \%$ giemsa and left for $30-60$ minutes on room temperature before washed by aquades and left to dry. Chromosome observed by $400 x$ and $1000 x$ magnification and photographed. Chromosomes characterized including chromosome numeration, $p, q$, absolute length, centromere index, RLK value, and R value (Ruas et al., 1995.; Levan et al., 1964; Brown, 1972).

\section{RESULTS AND DISCUSSION}

Characterization of chromosome of Xenochophis vittattus was studied in prometaphase obtained from colchicinized leukocyte nuclei. We obtained 3 best results which are represented to all specimens collected so far. Result showed there were so many cells within interphase, whereas the best part for observing chromosomes is at prometaphase due to diluted nuclei and thickening of chromosomes. Interphase marked by cell at its normal shape, consist of nuclei and cytoplasm, nuclei color can be distinguished easily from cytoplasm. At this rate, genetic materials of a cell are doubled. Prophase marked by expanded volume of nuclei followed by opaqueness nuclei. Nuclei dissolved at the beginning of prometaphase, which allow chromosomes to disperse in cytoplasm. Prometaphase ends when chromosomes lined up in the centre of cell paired with their homologues, entering metaphase. Anaphase marked by chromosomes withdrawal to 2 different poles, until cell ready to divide 
into telophase (Figure 1).

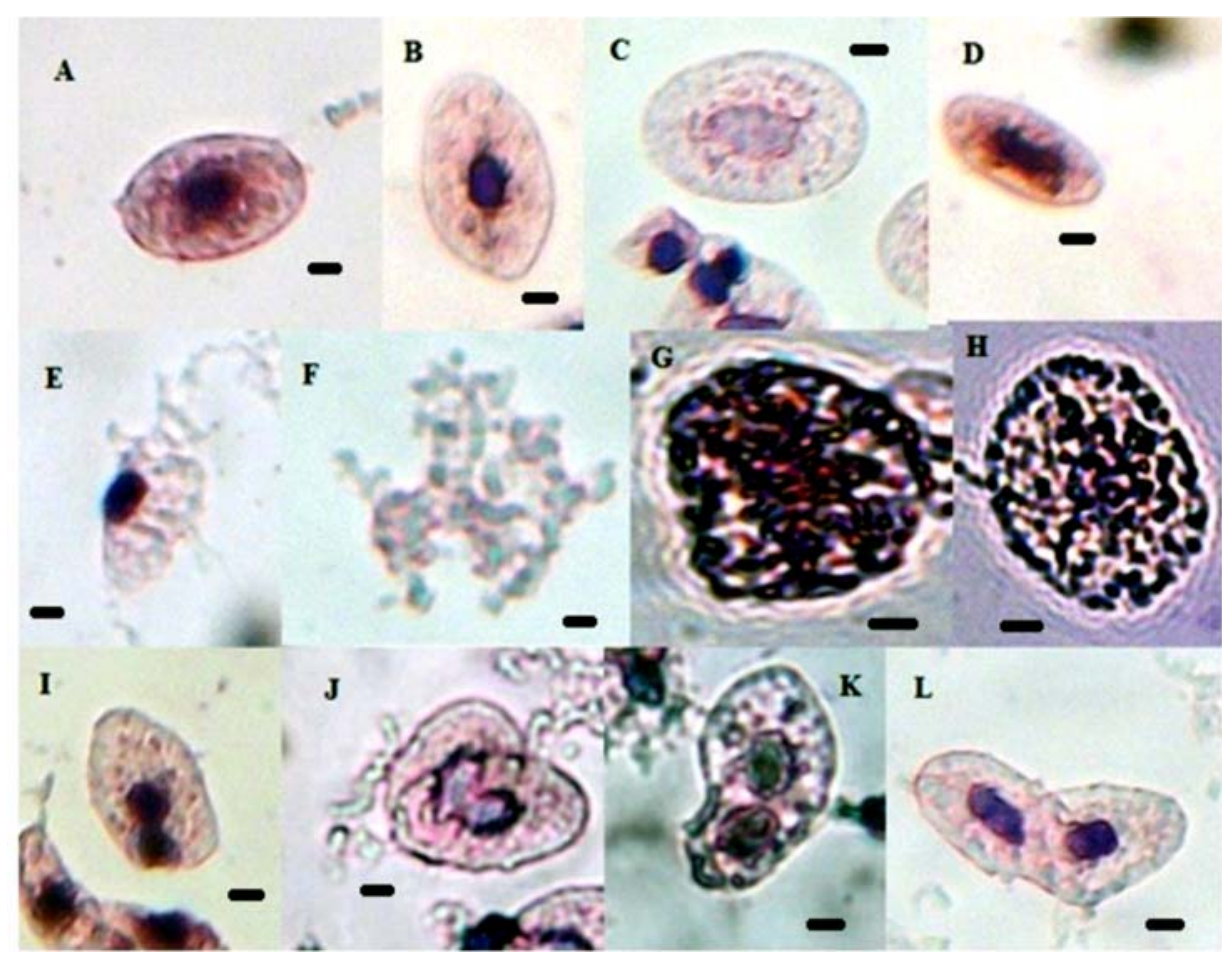

Figure 1. Striped keelback leucocyte cycle observed: interphase (A \& B), prophase (C \& D), prometaphase $(E \& F)$, metaphase $(G \& H)$, anaphase $(I \& J)$, telophase $(K \& L)$. Bar= $1 \mu \mathrm{m}$

Chromosomes of Xenochrophis vittattus were counted and calculated for their numerary, absolute length, centromere index, $R$ value, RLK value. The research showed that Xenochrophis vittattus has 17 pairs of homologous chromosome including microchromosomes (Figure 2-4). This result positively related with the late study of other specieses of the same Genus, hence chromosome numerary is closely related to snake relationship which share the same group especially at same Genus (Darnaedi, 1991).
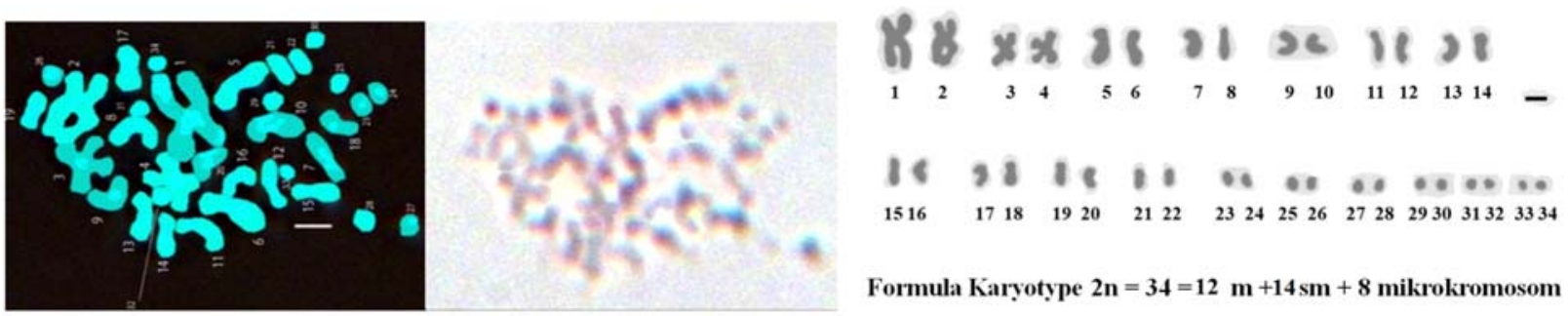

Figure 2. Chromosome observation of Striped keelback A. Bar $=1 \mu \mathrm{m}$
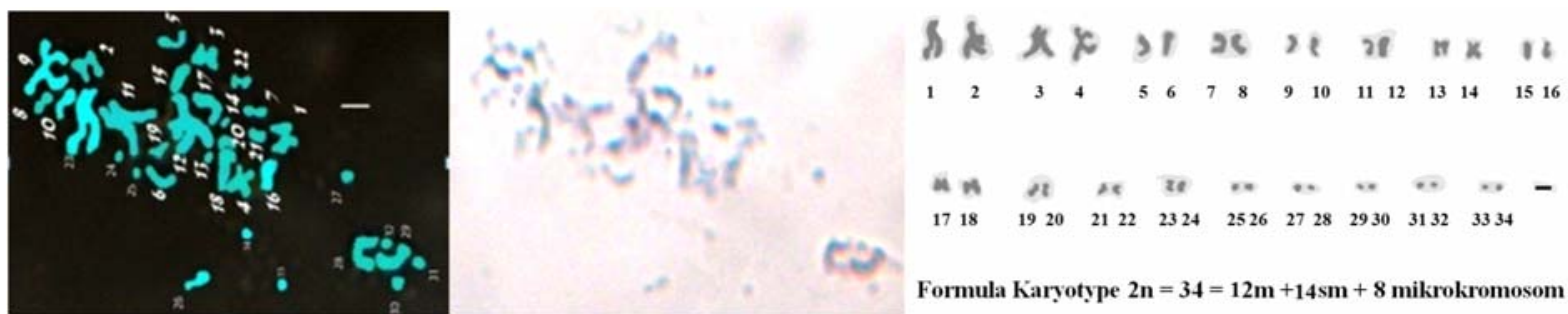

Figure 3. Chromosome observation of Striped keelback B. Bar $=1 \mu \mathrm{m}$ 

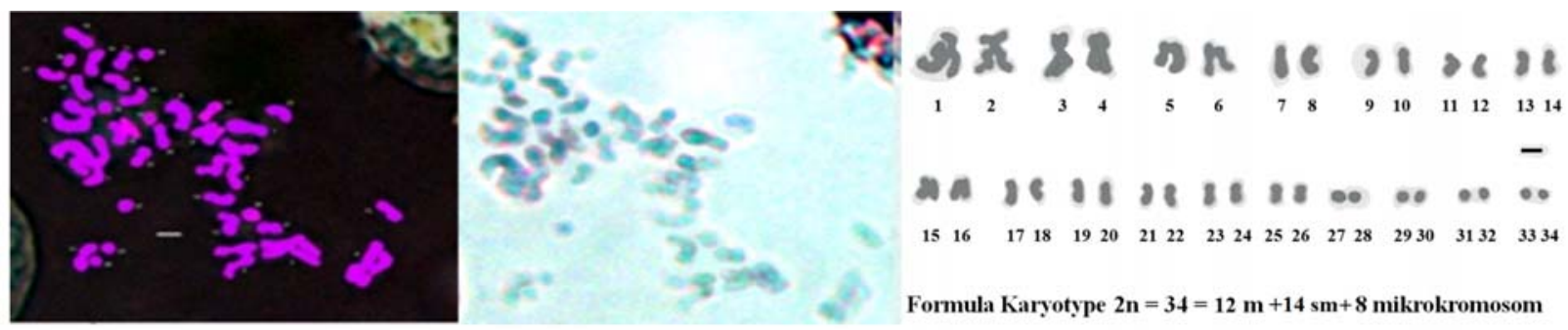

Figure 4. Chromosome observation of Striped keelback C. Bar $=1 \mu \mathrm{m}$

Chromosome resulted in this study edited by Photoshop X3 for better sight and rearranged by size order. Chromosome length calculated by software Autocad map 3D 2009, whereas further calculation resulting absolute length, centromere index, $R$ value and $R L K$ value were calculated by using Michrosoft excel 2007. Further calculation showed that Xenochrophis vittattus 17 pairs of homologous chromosome, 6 pairs were metacentric, 7 pairs were submetacentric, and 4 pairs were microchromosome which are not possible to be caunted. Specimen A showed the longest chromosome was 3,1187 $\mu \mathrm{m}$ which the shortest one was 0,6022 $\mu \mathrm{m}$ (Attachment a ). Whereas specimen B has the longest chromosome at 3,0214 $\mu \mathrm{m}$ and the shortest one was 0,4020 $\mu \mathrm{m}$ (Attachment b). specimen $\mathrm{C}$ has the longest chromosome at 3,0364 which the shortes was 0,4944 (Attachment C). Further calculation on this study have been collected into one average data (Table 1).

Table 1. Collective average data for characterization of chromosome Xenochrophis vittattus

\begin{tabular}{|c|c|c|c|c|c|c|c|c|c|}
\hline $\begin{array}{c}\text { No. } \\
\text { pasangan } \\
\text { kromosom }\end{array}$ & $\begin{array}{c}p \\
(\mu \mathrm{m})\end{array}$ & $\begin{array}{c}\text { Std } \\
\text { Dev } \\
p(\mu \mathrm{m})\end{array}$ & $\begin{array}{c}q \\
(\mu \mathrm{m})\end{array}$ & $\begin{array}{c}\text { Std } \\
\text { Dev } \\
q(\mu \mathrm{m})\end{array}$ & $\begin{array}{c}p+q \\
(\mu m)\end{array}$ & $\begin{array}{l}\text { Std } \\
\text { Dev } \\
\\
p+q\end{array}$ & $\begin{array}{r}\text { IS } \\
(\mu \mathrm{m})\end{array}$ & RLK & BK \\
\hline 1 & 1,2749 & 0,0218 & 1,6586 & 0,1554 & 2,9336 & 0,1772 & 43,4599 & 1,301 & $M$ \\
\hline 2 & 1,1199 & 0,032 & 1,287 & 0,0736 & 2,407 & 0,1056 & 46,5302 & 1,1491 & $M$ \\
\hline 3 & 0,6549 & 0,0049 & 1,2306 & 0,0115 & 1,8856 & 0,0163 & 34,7336 & 1,879 & SM \\
\hline 4 & 0,5739 & 0,0302 & 1,1384 & 0,0385 & 1,7123 & 0,0687 & 33,5157 & 1,9837 & SM \\
\hline 5 & 0,526 & 0,0257 & 1,0127 & 0,024 & 1,5387 & 0,0497 & 34,1863 & 1,9251 & SM \\
\hline 6 & 0,4702 & 0,0023 & 1,0098 & 0,0142 & 1,48 & 0,0165 & 31,7711 & 2,1475 & SM \\
\hline 7 & 0,4804 & 0,0041 & 0,9534 & 0,0269 & 1,434 & 0,031 & 33,5042 & 1,9847 & SM \\
\hline 8 & 0,4442 & 0,0006 & 0,8926 & 0,0657 & 1,3367 & 0,0664 & 33,2285 & 2,0095 & SM \\
\hline 9 & 0,4224 & 0,0129 & 0,8252 & 0,0187 & 1,2477 & 0,0315 & 33,8577 & 1,9535 & SM \\
\hline 10 & 0,5021 & 0,017 & 0,6307 & 0,0256 & 1,1329 & 0,0425 & 44,3246 & 1,2561 & $M$ \\
\hline 11 & 0,4749 & 0,0181 & 0,564 & 0,0344 & 1,039 & 0,0525 & 45,7127 & 1,1875 & $M$ \\
\hline 12 & 0,3972 & 0,0277 & 0,4658 & 0,0061 & 0,863 & 0,0216 & 46,0241 & 1,1728 & $M$ \\
\hline 13 & 0,3568 & 0,0144 & 0,3951 & 0,0145 & 0,7519 & 0,0289 & 47,4574 & 1,1071 & $M$ \\
\hline 14 & 0 & 0 & 0 & 0 & 0,633 & 0,0295 & 0 & 0 & \\
\hline 15 & 0 & 0 & 0 & 0 & 0,5942 & 0,0085 & 0 & 0 & \\
\hline 16 & 0 & 0 & 0 & 0 & 0,5375 & 0,0133 & 0 & 0 & \\
\hline 17 & 0 & 0 & 0 & 0 & 0,5088 & 0,013 & 0 & 0 & \\
\hline
\end{tabular}

Table 1 showed us the average calculation on every chromosome hence obtained a single collective data which represent to all specimen used in this study. It told us that the average amount of the longest chromosome was 2,9336 $\pm 0,1772 \mu \mathrm{m}$, while the shortest one was $0,5088 \pm 0,013 \mu \mathrm{m}$. chromosome of striped keelback has 17 pairs of homologous chromosome consist of 6 pairs of metacentric, 7 pairs of submetacentric, and 4 pairs of microchromosom, so that the karyotipe formula of this snak is $2 n=34=12 m+14 s m+8$ 
microchromosome. The chromosome amount was similar with studies about Natrix group reported before, as Rossman \& Eberle (1977) reported that some Natrix species distributed in Europe have 17 pairs of chromosome, some of Natrix distributed un North America have 18 pairs of chromosome, whereas some Natrix distributed in Asia have been known for having 21-23 pairs of chromosome.

Chromosome is a basic shape of genetic material in eukaryotic cell. Amount, shape, and any other characteristic related to chromosomes comparation lead to relationship among organism. The more likely the chromosome of two organisms the more related they are. Chromosome shape and position of centromere reflect its development on evolution. Organism which dominated by telocentric chromosome notably more develops than metacentric does. Xenochrophis vittattus which is dominated by metacentric but some of them lead to terminating centromeres showed submetacentric is reflect a development of snake in evolution. There was also various size of chromosome from chromosome number one to chromosome number 34 . The more various the size of the chromosome, the more $R$ value it will be, by means, the more develop it be (Ezaz et al., 2006).

Table 2. Average of $\mathrm{R}$ value of Xenochrophis vittattus

\begin{tabular}{cccc}
\hline Sample & $\begin{array}{c}\text { Average length of the } \\
\text { longest chrom. pair }\end{array}$ & $\begin{array}{c}\text { Average length of the } \\
\text { shortest chrom. pair }\end{array}$ & $\mathbf{R}$ \\
\hline Specimen A & $3,0188 \pm 0,1414$ & $0,6024 \pm 0,0002$ & 5,0113 \\
Specimen B & $2,8955 \pm 0,1781$ & $0,4036 \pm 0,0022$ & 7,1742 \\
Specimen C & $2,8864 \pm 0,2121$ & $0,5204 \pm 0,0366$ & 5,5465 \\
& Total & & 17,732 \\
\hline & Average & $5,9106 \pm 1,1265$ \\
\hline
\end{tabular}

Table 2 told us ration of the longest pair of the chromosome to the shortest one ( $R$ value). $R$ value show size variation on one chromosome set. The less $R$ value means the less size variation, vice versa. Table 2 clearly showed us that $R$ value of Xenochrophis vittattus was $5,9106 \pm 1,1265$. But there were some chromosome could not be calculated for their very small sized. Those chromosomes were named microchromosome due to its small size that could not be determinate the centromere of them and also their actual length.

Based on early explanation, the characteristic of chromosome of Xenochrophis vittattus from Piyungan, Bantul, Daerah Istimewa Yogyakarta can be seen at table 2.

Table 3. Characterization of chromosome of Striped keelback from Piyungan, Bantul, DIY

\begin{tabular}{lc}
\hline \multicolumn{1}{c}{ Chromosomal character } & Size \\
\hline Karyotype formula & $2 \mathrm{n}=2 \mathrm{x}=34=12 \mathrm{~m}+14 \mathrm{sm}+8$ microchrom \\
Absolut length of chrom. pair & The shortest $: 0,5088 \pm 0,013 \mu \mathrm{m}$ \\
& The longest : $2,9335 \pm 0,1772 \mu \mathrm{m}$ \\
Length of long arm pair & The shortest : $0,3951 \pm 0,0146 \mu \mathrm{m}$ \\
& The longest : $1,6586 \pm 0,1554 \mu \mathrm{m}$ \\
Length of short arm pair & The shortest : $0,3568 \pm 0,0144 \mu \mathrm{m}$ \\
& The longest : $1,2749 \pm 0,0218 \mu \mathrm{m}$ \\
\hline $\mathrm{R}$ value & $5,9106 \pm 1,1265$ \\
\hline
\end{tabular}


We provide the chart to help reader imagine and compare the actual size of each chromosome:

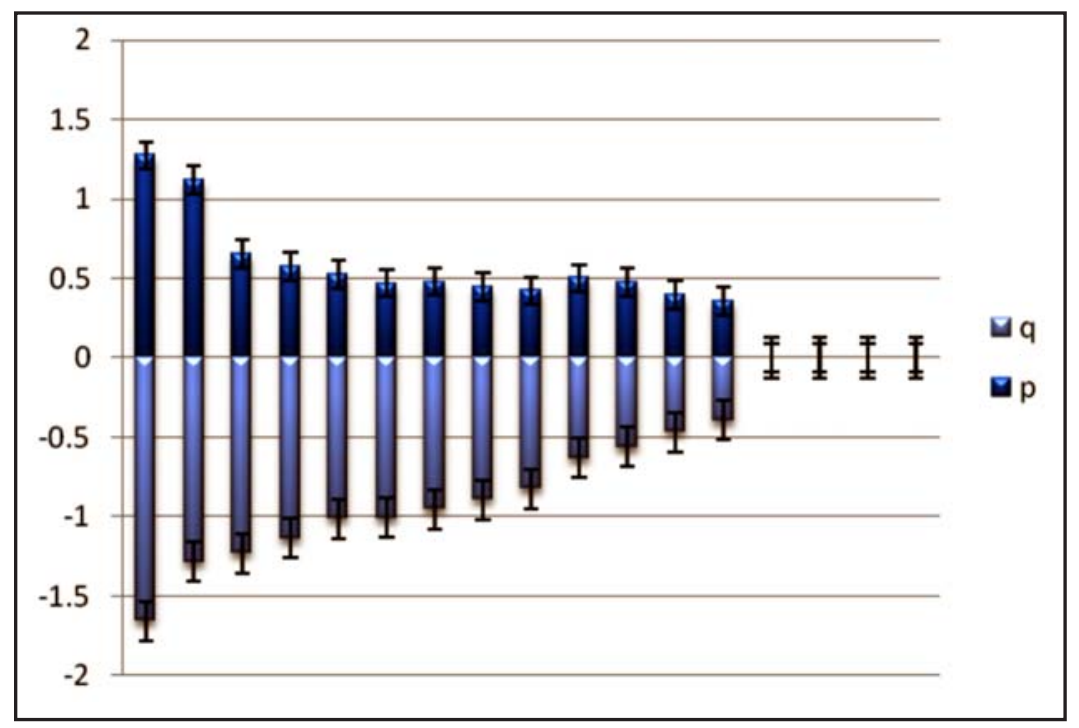

Figure 5. Schematic idiogram representing actual size among the chromosomes.

\section{REFERENCES}

Amemiya, C.T., J.W. Bickham, and J.R. Gold. 1984. A Cell Culture Technique For Chromosome Preparation in Cyprinid Fishes. Copeia $1: 232-235$.

Bergman, R.A.M. 1950. The Anatomy of Natrix Vittatta (L.). Zoologische Mededelingen.

Rijksmuseum van Natuurlijke Historie te Leiden Deel XXXI (2) : 13-14.

Brown, W.V. 1972. Text Book of Cytogenetics. C.V. Mosby Company. London.

Cole, C.J., and C. Gans. 1997. The Karyotype of Dibamus novaeguineae (Squamata:

Dibamidae). Herpetologica 53 (2) : 229-232.

Darnaedi, D. 1991. Kromosom dalam Taksonomi. Herbarium Bogoriense-Puslitbang Biologi-LIPI. Bogor.

Eberle, W.G. 1971. Comparative Chromosomal Morphology of the New World Natricine Snake Genera Natrix and Regina. Herpetologica 28 (2) : 98-105.

Ezaz, T., R. Stiglec, F. Veyrunes, and J.A.M. Graves. 2006. Relationship between Vertebrate ZW and XY Sex Chromosome Systems. Current Biology 16 : R736-R743

Gazali, W.H. 1914. The Common Snake of India and Burma and How To Recognize Them. Pioner Press. Allahabad.

Hoesel, J.K.P. van. 1959. Ophidia Javanica. Percetakan Archipel. Bogor.

Itoh, M., M. Sasaki, and S. Makino. 1970. The Chromosome of Some Japanese Snakes, With Special Regard to Sexual Dimorphism. J. Genetic. Japan 45 (2) : 121-128.

Levan, A., K. Fredga, and A.A. Sanberg. 1964. Nomenclature for Centromeric Position on Chromosom. Hereditas $52:$ 201-220.

Rooij, N. de. 1915. The Reptiles of the Indo-Australian Archipelago Vol 2; Ophidia. Brill, Leiden.

Rossman, D.A., and W.G. Eberle. 1977. Partition of the Genus Natrix, with Preliminary Observations on Evolutionary Trends in Natricinae Snakes. Herpetologica 33 : 34-43. 
Ruas, C.F., P.M. Ruas. N.I. Matzenbacher, G. Ross, C. Bernini, and A.L.L. Vanzela. 1995. Cytogenetic Studies of Some Hypochoeris Spesies (Compositae) from Brazil. American Journal of Botany 82 (3) : 369-375.

Trinco, L.A., and H.M. Smith. 1971. The Karyologi of Ophidian (review). Transactions of the Kansas Academy of Science 74 (2) : 140-144. 